\title{
ARTIGOS
}

\section{METODOLOGIA PARA INCLUSÃO DOS PRINCÍPIOS DE SUSTENTABILIDADE NO ENSINO DE DESIGN DE PRODUTO}

\section{METHODOLOGYFORINCLUSIONOFSUSTAINABILITYPRINCIPLESINPRODUCTDESIGNTEACHING}

ITAMAR FERREIRA DA SILVA, Dr. | UFCG

THAMYRES OLIVEIRA CLEMENTINO, M.SC. | UFCG

LETÍCIA FREIRE NEGROMONTE | UFCG

\begin{abstract}
RESUMO
O presente artigo expõe a utilização de uma metodologia específica para a inclusão do conceito de Life Cycle Design no primeiro período do Curso de Design da Universidade Federal de Campina Grande. A experimentação foi dividida em três etapas: exercícios para completar desafios, estudos de sistemas funcionais e desenvolvimento de produto com abordagem sustentável. Cada etapa seguiu um propósito pré-definido que culminou ao final do período com objetos confeccionados em papelão corrugado, com características de DO IT YOURSELF, montado sem uso de cola ou outros elementos estruturantes.
\end{abstract}

PALAVRAS CHAVE: Metodologia; Graduação em design; projeto; design para a sustentabilidade; Life cycle design

\section{ABSTRACT}

This article presents the use of a specific methodology for the inclusion of the concept of Life Cycle Design in the first period of the Design Course of the Universidade Federal de Campina Grande. The experiment was divided into three stages: exercises to complete challenges, functional systems studies and sustainable approach product development. Each stage followed a pre-defined purpose that culminated at the end of the period with objects made of corrugated cardboard, with characteristic of DO IT YOURSELF, assembled without the use of glue or other structuring elements.

KEY WORDS: Methodology; Degree in design; design project for sustainability; Life cycle design 


\section{INTRODUÇÃO}

O crescimento da problemática ambiental gerou a necessidade de melhorias na relação entre o homem e o meio ambiente, o que fomentou discussões sobre a "sustentabilidade", definida em 1987 no relatório Brundtland da ONU como o desenvolvimento que supre as necessidades atuais sem comprometer as capacidades das gerações futuras suprirem as suas próprias. Para Manzini e Vezzoli (2011), é intrínseca a esta abordagem o desenvolvimento sustentável, que visa superar o modelo de bem-estar baseado no uso excessivo de capital natural, objetivando integrar as ações humanas a resiliência do planeta. Na busca por efetivar este paradigma de desenvolvimento, aspira-se integrar as dimensões ambiental, socioética e econômica e política a fim de revelar o papel de cada uma em prol de um novo modelo de bem estar, que desta vez esteja pautado na coerência entre o consumir e os limites ambientais.

Para impulsionar e viabilizar esta transição é necessário à atuação de vários atores que, segundo Manzini (2008), busquem facilitar o processo. Entre eles encontra-se o designer, que de acordo com Kazazian (2005), tem papel importante para a construção de novas relações entre o meio ambiente e o consumo, apresentando potencial para gerar soluções que não demandem a destruição do meio ambiente, mas sim, a busca por caminhos que conduzam a uma economia "leve", onde haja integração entre as dinâmicas naturais e os produtos produzidos para o homem. Isto, de acordo com Manzini (2008), ocorre porque o design apresenta grande potencial para tornar-se parte da solução, já que em seu código genético está registrada a ideia de que sua razão de ser é melhorar a qualidade do mundo.

Mas, para a aplicação dos princípios do design para a sustentabilidade com foco na dimensão ambiental, é necessário a ingressão em níveis progressivos de redução dos impactos ambientais e de alteração na mudança de hábitos e comportamento dos consumidores. De acordo com Santos et. al (2018), inicia-se pela busca na melhoria dos fluxos de produção e consumo, passando para o foco no desenvolvimento de produtos por meio do redesign ambiental ou pelo design de produtos inteiramente novos, chegando ao sistema produto-serviço com ênfase na desmaterialização, que permitirá atingir novos cenários de consumo suficiente, em que propõe-se novos estilos de vida com forte apelo à sustentabilidade. $O$ avanço nestes níveis, de acordo com Vezzoli (2010) depende primeiramente de o designer aprender a desenvolver produtos e serviços ambientalmente sustentáveis, promovendo assim, novas configurações entre diferentes atores favorecendo o surgimento de soluções inovadoras capazes de convergir para interesses ambientais e econômicos.
Pazmino e Santos (2017), afirmam que a aplicação da abordagem da sustentabilidade no desenvolvimento de produtos faz-se cada vez mais urgente, demandando também uma forma inovadora de ensinar, conduzir e gerar os projetos, que permita que toda a complexidade inerente à sustentabilidade seja atendida. Mas, de acordo com as autoras, a trajetória do design no Brasil não se atentou ao novo paradigma ambiental, sobretudo no âmbito educacional, que tratou o tema com certo descaso nas definições de diretrizes curriculares e elaboração de currículos nos cursos de design, em que disciplinas relacionadas ao meio ambiente e sustentabilidade não são consideradas relevantes.

Para Calegari e Oliveira (2017), verifica-se que a abordagem da sustentabilidade nos cursos de design é realizada em disciplinas específicas ou como afirma Pazmino e Santos (2017), são normalmente oferecidas em fases avançadas, disciplinas complementares ou simplesmente não existem, o que gera, segundo as autoras, um aluno sem contato com a temática, que por sua vez não refletirá sobre suas ações projetuais e decisões tomadas ao longo do projeto, o que potencialmente o fará impactar o meio ambiente a partir da execução dos modelos exigidos pelo curso, protótipos, e no mercado de trabalho. As autoras seguem afirmando que o tema "sustentabilidade" deveria ser pensado de forma interdisciplinar, percorrendo todo o curso de forma transversal, integrando os conteúdos em uma visão mais holística, inovando nos processos metodológicos, o que é exposto também por Calegari e Oliveira (2017), ao afirmar que:

Considera-se relevante que os conceitos de sustentabilidade sejam trabalhados também dentro de outras disciplinas, como as de projeto, em que os estudantes têm a oportunidade de projetar levando em consideração os fatores que minimizem impactos ambientais, sociais e econômicos. Para isso, podem ser utilizadas estratégias de ecodesign, como desenvolvimento de produto voltado para a reciclagem e a reutilização, a redução de materiais, o uso de materiais locais, a escolha por processos de fabricação de baixo custo, e outros que impactem positivamente nas esferas ambiental, social e econômica abordadas na sustentabilidade.

A partir dessas estratégias é possível aspirar um aluno mais atento às questões ambientais que considere durante todo o curso da graduação, aspectos projetuais inerentes à sustentabilidade. Contribuindo com a inserção de profissionais mais conscientes no mercado de trabalho e o desenvolvimento de produtos mais coesos com a resiliência ambiental.

Este artigo apresenta um método desenvolvido para a disciplina de Projeto I do curso de design de produto da UFCG, cujo objetivo consiste em abordar a sustentabilidade de forma inovadora e transversal em turmas de 
primeiro período composta por discentes recém-ingressados a universidade. São detalhadas as etapas adotas para aplicação do método bem como os resultados alcançados no decorrer da disciplina a fim de que possa ser replicado em outras instituições de ensino.

\section{REFERÊNCIAL TEÓRICO}

De acordo com Kazazian (2005) não existe um produto totalmente ecológico, já que todos apresentam algum tipo de impacto ao meio ambiente, porém, a idealização de projetos mais sustentáveis implica na redução dos danos ambientais gerados pelo produto durante todo o seu ciclo de vida. Para que isto ocorra, Manzini e Vezzoli (2011) expõem a necessidade de lucidez acerca das etapas envolvidas no processo de produção, que vão desde a obtenção da matéria-prima, até o descarte pós-uso. Segundo os autores "podemos contar toda a vida de um produto como um conjunto de atividades e processos, cada um deles absorvendo uma quantidade de matéria e energia", para eles "considerar o ciclo de vida quer dizer adotar uma visão sistêmica de produto, para analisar o conjunto de inputs e dos outputs de todas as suas fases, com a finalidade de avaliar as consequências ambientais, econômicas e sociais".

Para Sampaio et. al (2018), ao se considerar questões de caráter ambiental para a concepção de um novo produto, é possível desenvolver um "produto intrinsecamente mais sustentável", o que pode ser alcançado a partir do conceito de Life Cycle Design (LCD), que consiste na concepção de um novo produto a partir de critérios ambientais, em que, afirma Manzini e Vezzoli (2011), todas as atividades para produção, distribuição, utilização e eliminação/descarte de produto são consideradas como uma só unidade, passando o "projeto do produto" para o "projeto do sistema-produto" em que "*...+ a intenção é criar uma ideia sistêmica de produto, em que os inputs de materiais e de energia bem como o impacto de todas as emissões e refugos sejam reduzidos ao mínimo possível, seja em termos quantitativos ou qualitativos, ponderando assim a nocividade de seus efeitos." (IBID, 2002, p.100). Para isto, busca-se a compreensão das seguintes fases:

\begin{tabular}{|l|l|}
\hline Fases & Definição \\
\hline Pré-produção & $\begin{array}{l}\text { - Estágio de manuseio das matérias-primas } \\
\text { utilizadas para produção dos componentes. } \\
\text { - Destacando a aquisição, transporte e transfor- } \\
\text { mação dos recursos em materiais e energia. }\end{array}$ \\
\hline Produção & $\begin{array}{l}\text { - Estágio onde ocorrem as transformações dos } \\
\text { materiais, o processo de montagem e seu acaba- } \\
\text { mento. Neste ponto, são desenvolvidos a pesquisa } \\
\text { a respeito do que se deseja produzir, seus controles } \\
\text { produtivos e o gerenciamento do projeto. }\end{array}$ \\
\hline
\end{tabular}

\begin{tabular}{|l|l|}
\hline Distribuição & $\begin{array}{l}\text { - Estágio que detém a embalagem; o trans- } \\
\text { porte; e a armazenagem do produto. }\end{array}$ \\
\hline Uso & $\begin{array}{l}\text { - Estágio de exercício da funcionalidade do } \\
\text { produto, em que, ou ele é utilizado por um } \\
\text { intervalo de tempo ou, obtém sua consumação } \\
\text { imediata de acordo com suas características. }\end{array}$ \\
\hline Descarte & $\begin{array}{l}\text { - Estágio responsável pelo destino final de } \\
\text { um produto após o seu período de uso. }\end{array}$ \\
\hline
\end{tabular}

Quadro 01 - Ciclo de vida

Fonte: adaptado de Manzini e Vezzoli, 2011.

O conhecimento acerca destas fases permite que o designer consiga projetar o ciclo de vida dos produtos a partir de estratégias que contribuam para o projeto de um produto que seja intrinsecamente mais sustentável. Segundo Manzini e Vezzoli (2011), um designer embasado nestes conhecimentos terá mais êxito para identificar os impactos ambientais dos produtos que está projetando, podendo atenuar com maior precisão os impactos negativos do mesmo ao meio ambiente.

\subsection{Estratégias para o Life Cycle Design}

O estudo conduzido por Manzini e Vezzoli (2011), propõe que para a adoção do Life Cycle Design seja empregada em uma série de estratégias que auxiliem o designer na tomada de decisão, de maneira que a condução de cada fase do projeto se torne mais coesa. As estratégias, ou linhas guia, estabelecidas pelos autores para a produção de um produto eco eficiente são as seguintes: 1) Minimização dos recursos; 2) Escolha de recursos e processos de baixo impacto ambiental; 3) Otimização da vida dos produtos; 4) Extensão da vida dos materiais; 5) Facilidade de desmontagem. Cada estratégia é seguida de parâmetros, que indicam caminhos para a aplicação do método em projetos de produto. Vale salientar que apenas uma estratégia torna-se insuficiente para atender a todos os requisitos ambientais de um projeto de produto, sendo necessário o estabelecimento de um mix, que garanta melhores resultados. Na minimização dos recursos, percebe-se a busca pela redução nas fases de produção, distribuição e durante o período de uso.

\begin{tabular}{|l|l|}
\hline Estratégias & Parâmetros \\
\hline Minimização o uso de & Minimizar o conteúdo ma- \\
recursos na produção & $\begin{array}{l}\text { terial de um produto; } \\
\text { Minimizar as perdas e os refugos; } \\
\text { Minimizar o consumo de energia } \\
\text { para a produção dos produtos; } \\
\text { Minimizar o consumo de recursos no } \\
\text { desenvolvimento dos produtos; }\end{array}$ \\
\hline
\end{tabular}




\begin{tabular}{|l|l|}
\hline $\begin{array}{l}\text { Minimizar o uso de } \\
\text { recursos na } \\
\text { distribuição }\end{array}$ & $\begin{array}{l}\text { Minimizar as embalagens; } \\
\text { Minimizar os consumos para o transporte; }\end{array}$ \\
\hline $\begin{array}{l}\text { Minimizar o con- } \\
\text { sumo de recursos } \\
\text { durante o uso }\end{array}$ & $\begin{array}{l}\text { São levados em consideração os re- } \\
\text { quisitos ambientais para a redução do } \\
\text { consumo de recursos durante o uso. }\end{array}$ \\
\hline
\end{tabular}

Quadro 02 - minimização dos recursos

Fonte: adaptado de Manzini e Vezzoli, 2011, p.118-134.

$\mathrm{Na}$ escolha de recursos e processos de baixo impacto ambiental, são abordadas tecnologias de transformação e de beneficiamento dos materiais, considerando-se a etapa de distribuição dos produtos:

\begin{tabular}{|l|l|}
\hline Estratégias & Parâmetros \\
\hline $\begin{array}{l}\text { A escolha dos } \\
\text { materiais e dos } \\
\text { processos de } \\
\text { baixo impacto }\end{array}$ & $\begin{array}{l}\text { Devem ser considerados os processos de } \\
\text { produção e de transformação de matérias, } \\
\text { os sistemas de distribuição e uso, e os trata- } \\
\text { mentos de eliminação final dos produtos. }\end{array}$ \\
\hline $\begin{array}{l}\text { A escolha } \\
\text { de recursos } \\
\text { energéticos de } \\
\text { baixo impacto }\end{array}$ & $\begin{array}{l}\text { Avaliar quais fontes energéticas dispo- } \\
\text { níveis fornecerão menor impacto am- } \\
\text { biental, em todo o ciclo do produto; }\end{array}$ \\
\cline { 2 - 2 } & $\begin{array}{l}\text { Adotar sistemas de transformação energé- } \\
\text { tica que explore ao máximo as capacidades } \\
\text { de gerar bem-estar para o ecossistema. }\end{array}$ \\
\hline
\end{tabular}

Quadro 03 - recursos e processos de baixo impacto

Fonte: adaptado de Manzini e Vezzoli, 2011, p.148-180.

$\mathrm{Na}$ escolha de recursos e processos de baixo impacto ambiental, são abordadas tecnologias de transformação e de beneficiamento dos materiais, considerando-se a etapa de distribuição dos produtos:

\begin{tabular}{|l|l|}
\hline Estratégias & Parâmetros \\
\hline $\begin{array}{l}\text { Projetar a } \\
\text { duração } \\
\text { adequada }\end{array}$ & $\begin{array}{l}\text { Projetar a vida útil do produto de acor- } \\
\text { do com a das suas partes; } \\
\text { Projetar a vida útil das partes de acordo com a du- } \\
\text { ração prevista para substituí-los durante seu uso; } \\
\text { Optar por materiais duráveis tendo em vis- } \\
\text { ta a necessidade e a vida útil do produto; } \\
\text { Evitar materiais permanentes } \\
\text { para funções temporárias. }\end{array}$ \\
\hline $\begin{array}{l}\text { Projetar a } \\
\text { segurança }\end{array}$ & $\begin{array}{l}\text { Minimizar o número de partes e componentes; } \\
\text { Simplificar os produtos; } \\
\text { Evitar junções frágeis na composi- } \\
\text { ção do produto como um todo. }\end{array}$ \\
\hline $\begin{array}{l}\text { Facilitar a } \\
\text { atualização } \\
\text { e a adapta- } \\
\text { bilidade }\end{array}$ & $\begin{array}{l}\text { Permitir a atualização das par- } \\
\text { tes do produto como um todo; } \\
\text { Projetar produtos permutáveis, modu- } \\
\text { lares e reconfiguráveis, em áreas de di- } \\
\text { mensão, serventia e estética. }\end{array}$ \\
\hline
\end{tabular}

\begin{tabular}{|c|c|}
\hline $\begin{array}{l}\text { Facilitar a } \\
\text { manutenção }\end{array}$ & $\begin{array}{l}\text { Facilitar a substituição das partes que ne- } \\
\text { cessitem de manutenção periódica, sim- } \\
\text { plificando o acesso e remoção; } \\
\text { Prover e facilitar a substituição dos com- } \\
\text { ponentes de forma mais ágil; } \\
\text { Prover sistemas para diagnosticar as par- } \\
\text { tes a passar por manutenção; } \\
\text { Projetar fácil manutenção no pró- } \\
\text { prio ambiente de uso; } \\
\text { Projetar procurando reduzir as ope- } \\
\text { rações de manutenção. }\end{array}$ \\
\hline $\begin{array}{l}\text { Facilitar a } \\
\text { reparação } \\
\text { e a } \\
\text { reutilização }\end{array}$ & $\begin{array}{l}\text { Predispor e facilitar e facilitar a remoção e retorno } \\
\text { das partes do produto que estão sujeitas a danos; } \\
\text { Projetar partes e componentes padronizados; } \\
\text { Projetar buscando facilitar o reparo no local de uso } \\
\text { Projetar a reutilização de partes auxiliares; } \\
\text { Incrementar a reutilização de partes } \\
\text { mais sujeitas a avarias e rupturas; } \\
\text { Projetar prevendo um segundo uso. }\end{array}$ \\
\hline $\begin{array}{l}\text { Facilitar a } \\
\text { remodelação }\end{array}$ & $\begin{array}{l}\text { Projetar a viabilidade da remoção, substituição } \\
\text { e a permuta das partes e dos componentes } \\
\text { dentro de uma mesma linha de produtos. }\end{array}$ \\
\hline $\begin{array}{l}\text { Intensificar a } \\
\text { reutilização }\end{array}$ & $\begin{array}{l}\text { Projetar produtos/serviços volta- } \\
\text { dos ao uso compartilhado; } \\
\text { Projetar produtos/serviços volta- } \\
\text { dos para o uso coletivo; } \\
\text { Projetar produtos com funções integradas; } \\
\text { Projetar produtos multifuncionais com } \\
\text { componentes comuns e substituíveis. }\end{array}$ \\
\hline
\end{tabular}

Quadro 04 - otimização da vida dos produtos

Fonte: adaptado de Manzini e Vezzoli, 2011, p. 188-208.

As estratégias para a extensão da vida dos materiais relacionam-se a transformação de matérias primas em secundárias e na incineração para uso de seu conteúdo energético:

\begin{tabular}{|l|l|}
\hline Estratégias & Parâmetros \\
\hline $\begin{array}{l}\text { Adotar a } \\
\text { reciclagem } \\
\text { em efeito } \\
\text { cascata }\end{array}$ & $\begin{array}{l}\text { Planejar e projetar o uso dos materiais reciclados } \\
\text { de forma que estes sejam aplicados de maneira se- } \\
\text { quencial em produtos de qualidades cada vez mais } \\
\text { inferiores até à exaustão da qualidade do material. }\end{array}$ \\
\hline $\begin{array}{l}\text { Escolher } \\
\text { materiais } \\
\text { com tecno- } \\
\text { logias de } \\
\text { reciclagem } \\
\text { eficiente }\end{array}$ & $\begin{array}{l}\text { Optar por materiais de fácil recuperação as } \\
\text { características das suas serventias iniciais; } \\
\text { Evitar o uso de materiais compostos, pre- } \\
\text { ferindo aqueles compatíveis com uma tec- } \\
\text { nologia de reciclagem mais eficiente; } \\
\text { Optar preferencialmente por polímeros ter- } \\
\text { moplásticos, substituindo os termorrígidos; } \\
\text { Projetar considerando a relação entre o } \\
\text { produto e o material a ser utilizado; } \\
\text { Evitar aditivos, utilizando termoplásticos } \\
\text { resistentes às temperaturas de uso. }\end{array}$ \\
\hline $\begin{array}{l}\text { Facilitar a } \\
\text { recolha e } \\
\text { o transporte } \\
\text { após o } \\
\text { uso }\end{array}$ & $\begin{array}{l}\text { Devem ser avaliadas todas as possibili- } \\
\text { dades tecnológicas e econômicas; } \\
\text { Projetar em relação ao sistema de recu- } \\
\text { peração dos produtos eliminados; } \\
\text { Minimizar o peso do produto; } \\
\text { Minimizar o volume e tornar compac- } \\
\text { táveis os produtos eliminados; } \\
\text { Informar ao usuário informações so- } \\
\text { bre o modo de descarte do produto. }\end{array}$ \\
\hline
\end{tabular}




\begin{tabular}{|l|l|}
\hline $\begin{array}{l}\text { Identificar os } \\
\text { materiais }\end{array}$ & $\begin{array}{l}\text { Codificar vários materiais para definir o seu tipo; } \\
\text { Fornecer informações complemen- } \\
\text { tares sobre a ideia do material; } \\
\text { Posicionar os códigos em lugares visíveis; } \\
\text { Fornecer informações complementares so- } \\
\text { bre a idade do material, número de recicla- } \\
\text { gens já efetuadas e os aditivos utilizados. }\end{array}$ \\
\hline $\begin{array}{l}\text { Minimizar o } \\
\text { número de } \\
\text { materiais } \\
\text { compatíveis } \\
\text { entre si }\end{array}$ & $\begin{array}{l}\text { Integrar as funções das partes de um ma- } \\
\text { terial, reduzindo o número de compo- } \\
\text { nentes e de materiais empregados; } \\
\text { Utilizar em um mesmo produto mate- } \\
\text { riais que sejam compatíveis entre si. }\end{array}$ \\
\hline limpeza & $\begin{array}{l}\text { Os materiais devem ser limpos para eliminar } \\
\text { as contaminações adquiridas pelo contato } \\
\text { com outros componentes ou derivadas de } \\
\text { operações de tratamento de superfícies. }\end{array}$ \\
\hline $\begin{array}{l}\text { Facilitar a } \\
\text { compostagem }\end{array}$ & $\begin{array}{l}\text { Os tipos de produtos que se adaptam a este } \\
\text { tipo de tratamento são caracterizados por } \\
\text { um alto percentual de materiais putrescí- } \\
\text { veis, ou seja, indicados à compostagem. }\end{array}$ \\
\hline combustão & $\begin{array}{l}\text { É útil proceder à incineração de um ma- } \\
\text { terial somente após este ter sido reci- } \\
\text { clado e reutilizado várias vezes. }\end{array}$ \\
\hline
\end{tabular}

Quadro 05 - facilitação da desmontagem

Fonte: adaptado de Manzini e Vezzoli, 2011, p. 222-240

Para a estratégia de facilitação da desmontagem, aborda-se o conceito de Design for Disassembly (DFD), que consiste em conceber e projetar produtos facilitando a sua desmontagem.

\begin{tabular}{|l|l|}
\hline Estratégias & Parâmetros \\
\hline $\begin{array}{l}\text { Minimizar e } \\
\text { facilitar as } \\
\text { operações para } \\
\text { a desmontagem } \\
\text { e separação }\end{array}$ & $\begin{array}{l}\text { Ao considerar a estrutura das conexões de } \\
\text { um produto, é investigada a possibilidade } \\
\text { de substituição de um componente sem } \\
\text { que seja necessário o desmonte de outros } \\
\text { ou ter de efetuar outras desmontagens. }\end{array}$ \\
\hline $\begin{array}{l}\text { Usar sistemas com } \\
\text { junções reversíveis }\end{array}$ & $\begin{array}{l}\text { Tem por finalidade esteder a } \\
\text { vida de um produto. }\end{array}$ \\
\hline $\begin{array}{l}\text { Usar sistemas de } \\
\text { união permanente } \\
\text { que possam ser } \\
\text { facilmente abertos }\end{array}$ & $\begin{array}{l}\text { É levado em consideração a sua aplica- } \\
\text { de impacto uso, a fim de reduzir o grau } \\
\text { para que seu dano para o reaprovei- } \\
\text { tamento seja o menor possível. }\end{array}$ \\
\hline $\begin{array}{l}\text { Prever tecnologias e } \\
\text { formas específicas } \\
\text { para a desmonta- } \\
\text { gem destrutiva }\end{array}$ & $\begin{array}{l}\text { É um método eficiente quando se deseja } \\
\text { uma rápida separação de alguns ma- } \\
\text { teriais ou no caso de eliminar insertos } \\
\text { incompatíveis com o material utilizado. }\end{array}$ \\
\hline $\begin{array}{l}\text { Minimizar o número } \\
\text { de materiais incom- } \\
\text { patíveis entre si }\end{array}$ & $\begin{array}{l}\text { Integrar as funções das partes de um } \\
\text { material, reduzindo o número de com- } \\
\text { ponentes e de materiais empregados; } \\
\text { Utilizar em um mesmo produto mate- } \\
\text { riais que sejam compatíveis entre si }\end{array}$ \\
\hline $\begin{array}{l}\text { Usar materiais fa- } \\
\text { quanente separáveis }\end{array}$ & $\begin{array}{l}\text { É necessário conhecer as tecnologias neces- } \\
\text { sárias para a separação desses materiais. }\end{array}$ \\
\hline
\end{tabular}

\begin{tabular}{|l|l|}
\hline $\begin{array}{l}\text { Usar insertos facil- } \\
\text { mente separáveis } \\
\text { em materiais } \\
\text { já triturados }\end{array}$ & $\begin{array}{l}\text { É necessário que os insertos incompatíveis } \\
\text { sejam facilmente removidos dos materiais } \\
\text { que são reciclados através de tecnologias }\end{array}$ \\
\hline $\begin{array}{l}\text { Facilitar a } \\
\text { combustão }\end{array}$ & $\begin{array}{l}\text { É útil proceder à incineração de um } \\
\text { material somente após este ter sido } \\
\text { reciclado e reutilizado várias vezes. }\end{array}$ \\
\hline
\end{tabular}

Quadro 06 - extensão da vida dos materiais

Fonte: adaptado de Manzini e Vezzoli, 2011, p. 254-267

\section{METÓDO E TÉCNICA}

A sustentabilidade é um conteúdo abordado de maneira superficial no ensino básico e fundamental, tendo destaque apenas em eventos como Feiras de Ciências ou em comemoração a Semana do Meio Ambiente. Esse afastamento da responsabilidade ambiental propicia a formação de indivíduos incapazes de visualizar os benefícios presentes na preservação do meio ambiente, tratando com descaso questões sobre o consumo consciente, desperdício dos recursos naturais, poluição e a destruição dos ambientes terrestres e aquáticos.

Nas universidades está percepção se agrava a partir da inexistência de conteúdos em disciplinas, que leve os discente ao questionamento do seu papel no contexto ambiental, salvo em alguns casos como disciplinas optativas conhecidas como Ciências do Ambiente.

No Curso de Design da Universidade Federal de Campina Grande/PB, o referido conteúdo é ministrado em disciplinas optativas (Design e Ecologia e Design e Desenvolvimento) que só podem ser cursadas quando o aluno se encontra praticamente no final do curso. Mostrando total descaso com a temática ambiental. Todavia, para amenizar essa situação e promover no início do curso de graduação a reflexão sobre a relação do design e as consequências ambientais resultante do desenvolvimento de produtos, foi proposto que na disciplina PROJETO 1 (primeiro período), fosse abordado em seus estágios, o ecodesign e o design sustentável, visando despertar nos alunos o uso da capacidade criativa, pertinente a profissão de designer, na concepção de produtos que levem em consideração os requisitos ambientais apresentados por Manzini e Vezzoli (2011), porém sem uma cobrança vinculada diretamente a esses requisitos, todavia sendo solicitada de forma indireta. Verificou-se a necessidade de preparar o aluno com conhecimentos prévio, para que o resultado final fosse satisfatório, sendo assim, a disciplina foi dividida em três estágios:

ESTÁGIO 1: Foram elaborados exercícios na forma de desafios, que tinham como objetivo principal apresentar ao aluno as potencialidades dos materiais e a suas limitações de uso na atividade projetual. Materiais como folha de papel comum, bandejas de isopor, canudos plásticos, fita adesiva, folha de papel craft e alfinetes foram utilizados 
com este objetivo. Os desafios eram iniciados e finalizados em sala de aula, sendo cronometrados para o controle do tempo de execução. Ao final da aula havia uma discussão referente aos resultados obtidos onde aspectos de produção, desperdício, reutilização, construção, modularidade, eram identificados e evidenciados para reflexão.

\begin{tabular}{l} 
EXERCíCIOS DO 10 Estágio \\
\hline Desafio 1: Com uma folha de papel A3 e uma tira de $50 \mathrm{~cm}$ de \\
fita adesiva confeccionar uma estrutura mais alta possível. \\
Desafio 2: Com uma folha de papel A3 e uma tira de 50 \\
cm de fita adesiva confeccionar uma estrutura que su- \\
porte o peso de tijolos a uma altura de $10 \mathrm{~cm}$. \\
Desafio 3: Com uma bandeja de isopor e uso de alfinetes confec- \\
cionar uma estrutura que suporte uma garrafa de água mineral \\
de 500 ml (cheia) a uma altura de 10 cm e inclinação de $45^{\circ}$. \\
Desafio 4: Com uma embalagem de isopor crie um objeto utilitário. \\
Desafio 5 - sketmodel de um mobiliário com uma folha \\
A4 de papel craft, 1 bandeja de isopor e 2 canudos. \\
Podemos destacar nestes desafios o uso limitado de material, onde \\
os alunos deveriam fazer mais com menos. Tentando alcançar o \\
desafio sem desperdício de tempo nem de matéria-prima, pois \\
os materiais não poderiam ser repostos. Outro ponto se refere à \\
quebra de paradigma sobre as propriedades físicas dos materiais \\
que podem ser evidenciadas e melhoradas a partir de técnicas de \\
encaixe e dobradura obtendo tanto flexibilidade como resistência, \\
sem a necessidade de incorporação de novos elementos externos.
\end{tabular}

Quadro 07 - Exercícios do $1^{\circ}$ Estágio

Fonte: Autores.

Nas Figuras 1 e 2 são apresentados dois exercícios com o objetivo de experimentar o uso do material em duas situações bem distintas, descontruindo a percepção sobre a fragilidade do papel. Em dado momento os exercícios exploravam a estabilidade e a verticalidade, em outro a resistência e a força. Vale enfatizar que as atividades eram em grupo, o que promovia a integração entre os alunos recém-chegados ao curso.
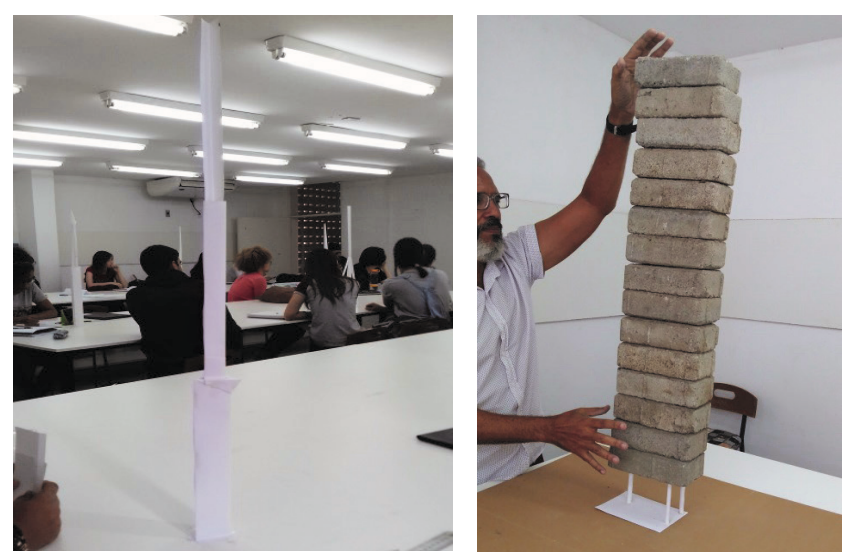

Figura 01 e 02 - Estruturas confeccionadas com uma folha A3 (75g) e $50 \mathrm{~cm}$ de fita adesiva Fonte: Autores (2018).
No Desafio 3 o material utilizado foi uma bandeja de isopor e 8 alfinetes. Neste exercício o artefato a ser construído possuía as características de um expositor para uma garrafa de água mineral (cheia), com peso definido de $500 \mathrm{~g}$. Vale enfatizar que o ângulo de $45^{\circ}$ deveria ser obtido sem o uso de instrumentos de medição (figura 3).

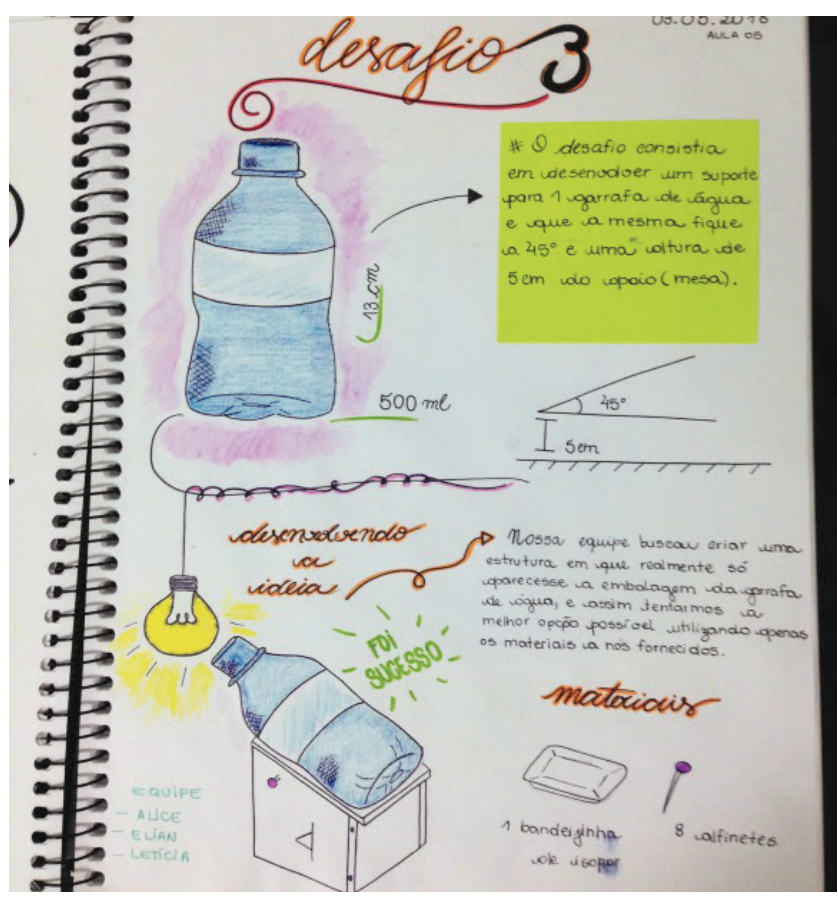

Figura 03 - Registro no sketchbook do Desafio 3

Fonte: Autores (2018)

No Desafio 4 eram utilizados uma embalagem de isopor para sanduiche e 2 espetos em madeira, onde os alunos poderiam cortar, virar, dobrar a estrutura, sem desconfigurá-la ao ponto de não ser reconhecida a origem do produto final. Neste desafio a criatividade era explorada, porém com a limitação visual e de material.

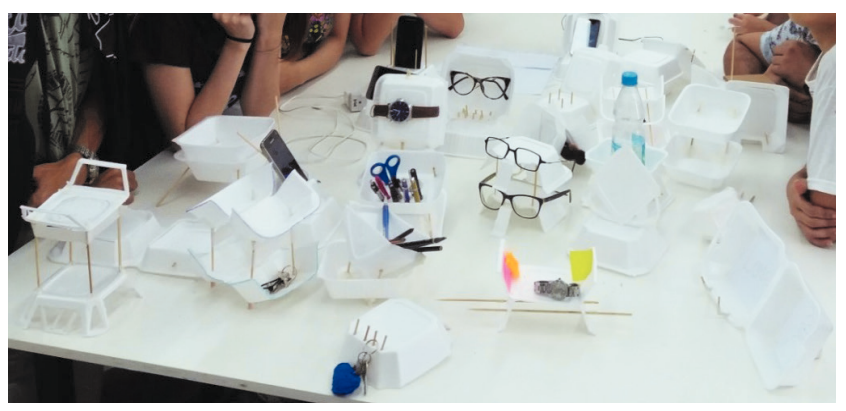

Figura 04 - Objetos utilitários em isopor

Fonte: Autores (2018).

O Desafio 5 consistiu em elaborar um sketmodel de um mobiliário com uma folha A4 de papel craft, 1 bandeja de isopor e 2 canudos de plástico. O objetivo deste 
exercício consistia em explorar as propriedades do papel craft e dos canudos (mais resistentes e maleáveis que o isopor). Neste momento os alunos necessitariam pensar onde aplicar cada material na estrutura desenvolvida.

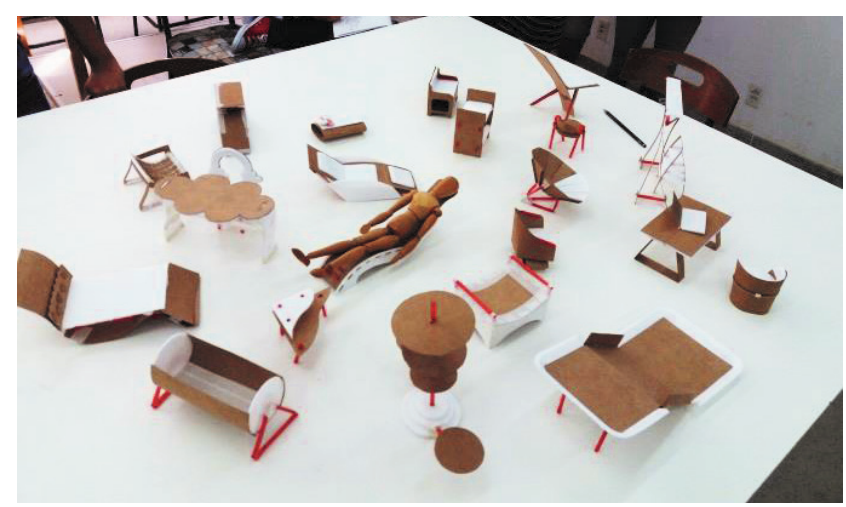

Figura 05 - sketchmodels

Fonte: Autores (2018)

ESTÁGIO 2: teve como foco a análise dos sistemas funcionais existentes nos produtos, destacando as partes e componentes, formas de união, travamento, extensão, etc. Buscando sempre detalhar como os elementos se relacionam para executar determinada função. Neste estágio os alunos desmontavam produtos, identificavam, classificavam e criavam sistemas funcionais. As aulas eram registradas no sketchbook conforme pode ser visto na sequencia de imagens a seguir.

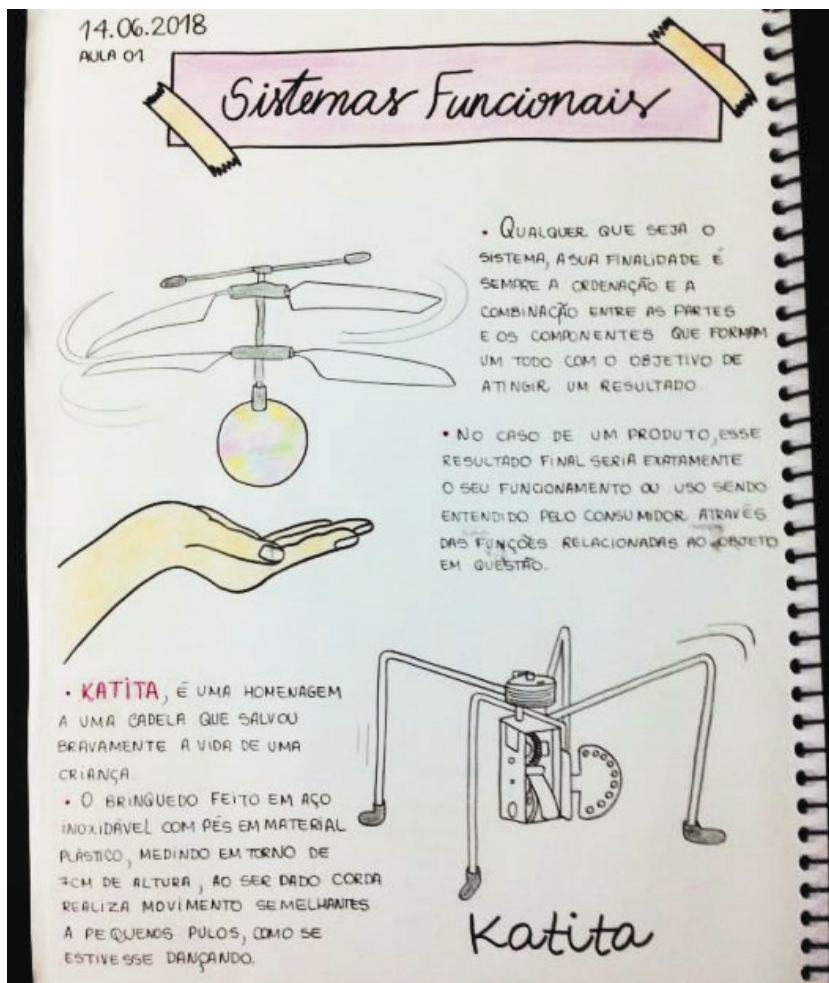

Figura 06 - Aula sobre produtos cujo sistema funcional se destaca mais que a forma Fonte: Autores (2018)

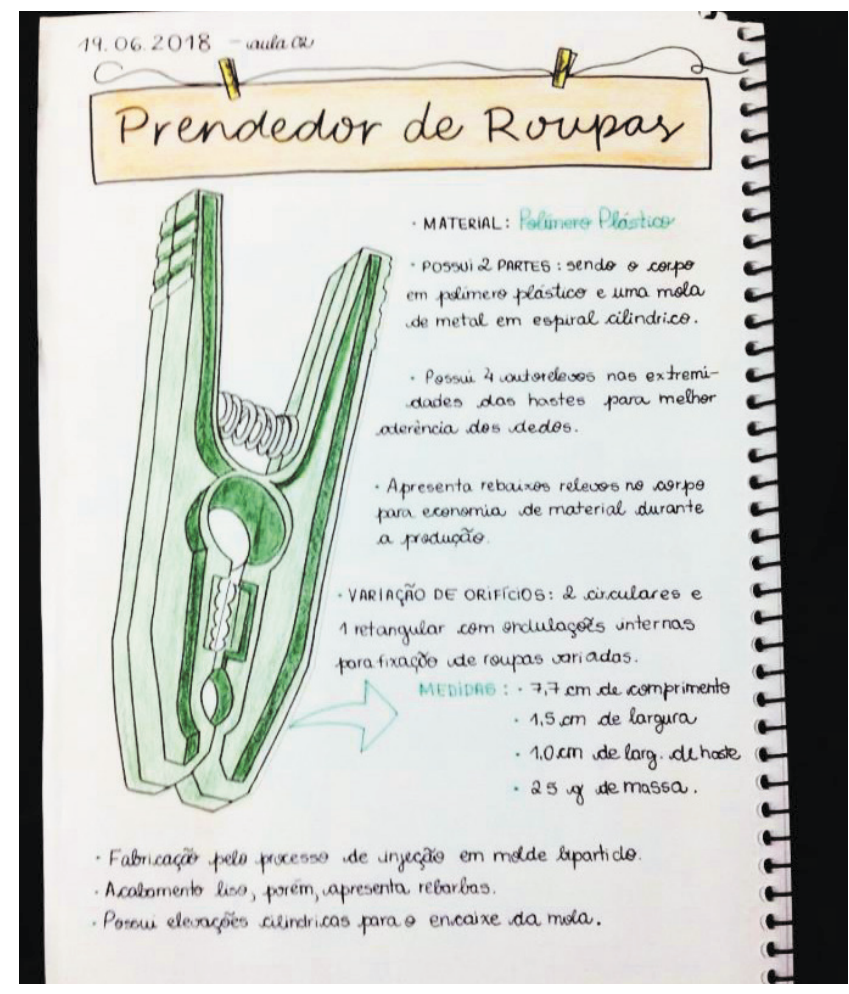

Figura 07 - Registro no sketchbook da análise de um prendedor de roupas. Fonte: Autores (2018).
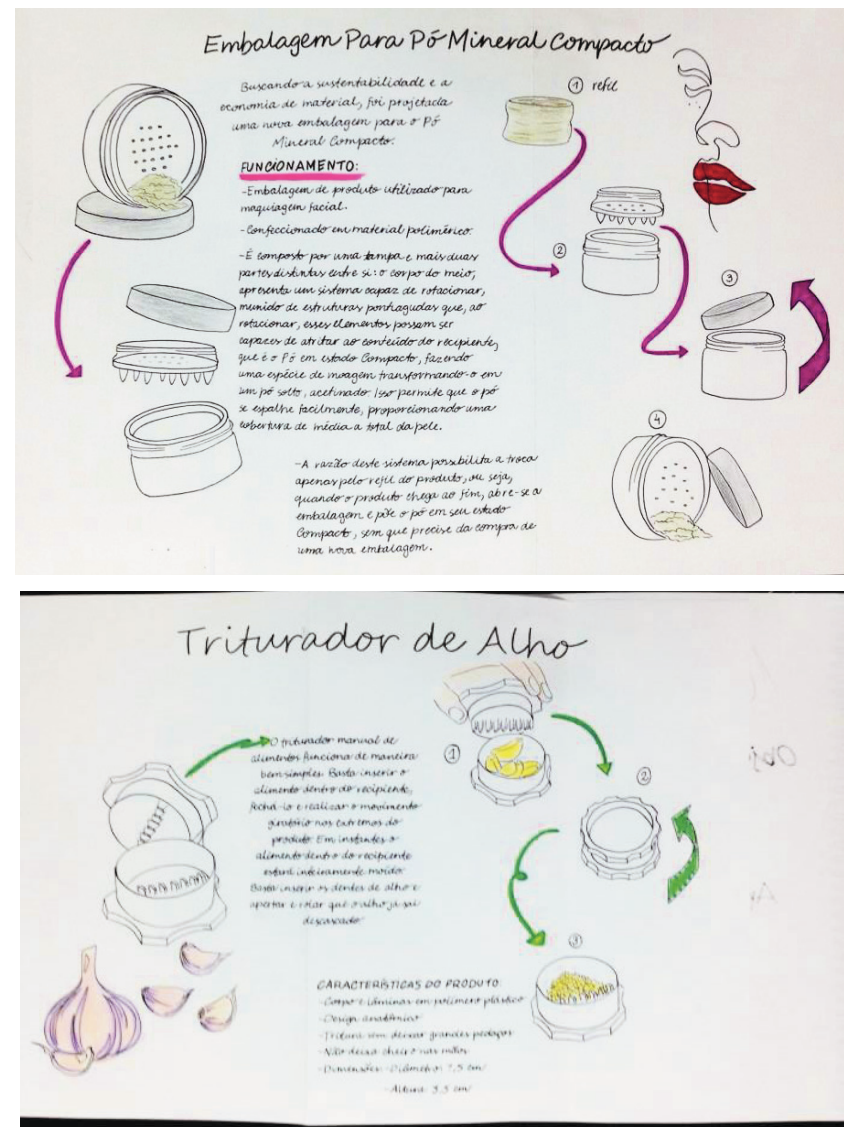

Figura 08 - : Estudo do funcionamento de um objeto e redesenho de outro produto utilizando 0 mesmo sistema funcional Fonte: Autores (2018). 

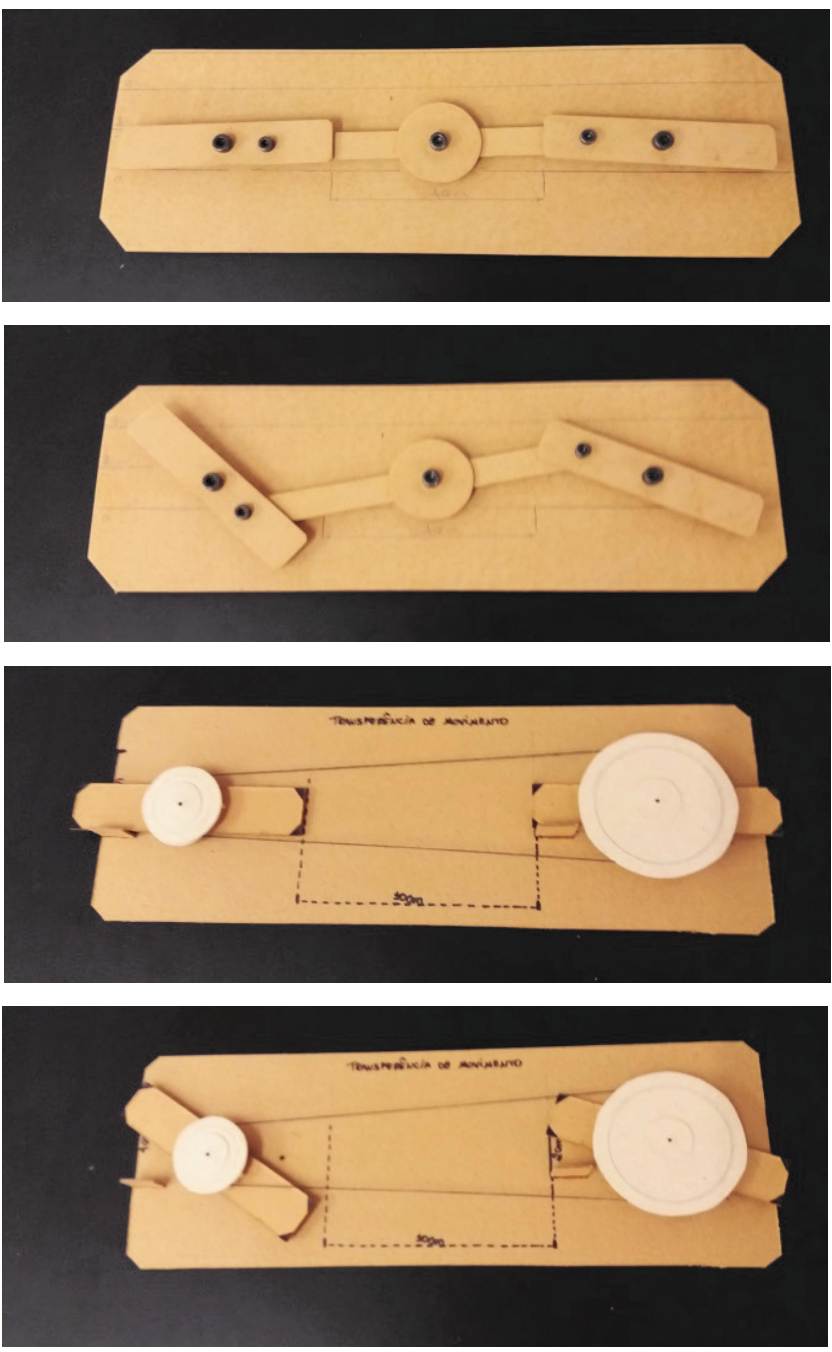

Figura 09 - Sistemas funcionais de transferência de movimento Fonte: Autores (2018).

Estas duas etapas da disciplina tinham como função preparar o discente para o $3^{\circ}$ estágio, onde cada grupo de alunos seria responsável pelo desenvolvimento de um produto com as seguintes características:

a) Confeccionado todo por encaixe em papelão corrugado e tubo de papelão;

b) Vir desmontado e sua montagem ser realizada apenas na hora da apresentação;

c) Não utilizar material para colar, fixar ou unir. Sendo permitido apenas o uso de fita crepe para dar acabamento ao produto.

Antes da fase de desenvolvimento do produto houve uma apresentação falando sobre ecodesign e design sustentável. Após discussão sobre 3 proposituras projetuais apresentadas pelos grupos, o professor passou a redirecionar os projetos, visando alcançar o maior número de requisitos descritos por Manzini e Vezzoli. Tais como:
Do Life Cicle Design se buscou: a) minimização dos recursos, programando a redução do uso de materiais e de energia; b) trabalhar com o mínimo de desperdício, criando plano de corte e a utilização de partes padronizadas que se repetem; e c) facilidade de desmontagem, permitindo a separação das partes e componentes e a necessidade de encaixes intuitivos e fáceis de serem executados.

Do quadro Minimização dos Recursos: reduzir o conteúdo de material de um produto simplificando sua forma e seus sistemas. Evitar perdas e refugos, sendo que partes consideradas descartes podem compor um sistema ou ser incorporado na estrutura.

Do quadro de estratégias para otimização da vida dos produtos: Reduzir as partes e componentes para haver uma simplificação da forma evitando junções frágeis na composição do produto. Prover e facilitar a substituição dos componentes de forma ágil, através de sistemas de encaixe sem uso de cola. Projetar partes e componentes padronizados que permitam sua replicação, redução no tempo de confecção e maior controle de qualidade e substituição.

Do quadro As estratégias para a extensão da vida dos materiais: o uso do papelão corrugado, pois é facilmente reciclado. Não utilizar materiais que possam retirar o aspecto sustentável do produto. Projetar considerando a relação entre o produto e o material, que por suas características físicas e químicas deva-se evitar o contato direto com alimentos.

E por fim, do quadro Facilitando a desmontagem foi direcionado: facilitar as operações para desmontagem e separação das partes, facilitando a substituição de seus componentes; integrar as funções das partes.

\section{RESULTADOS}

As atividades de concepção e desenvolvimento dos produtos foram realizadas em sala de aula com supervisão contínua do professor. Como exemplos do resultado da disciplina são apresentados quatro projetos a seguir: 

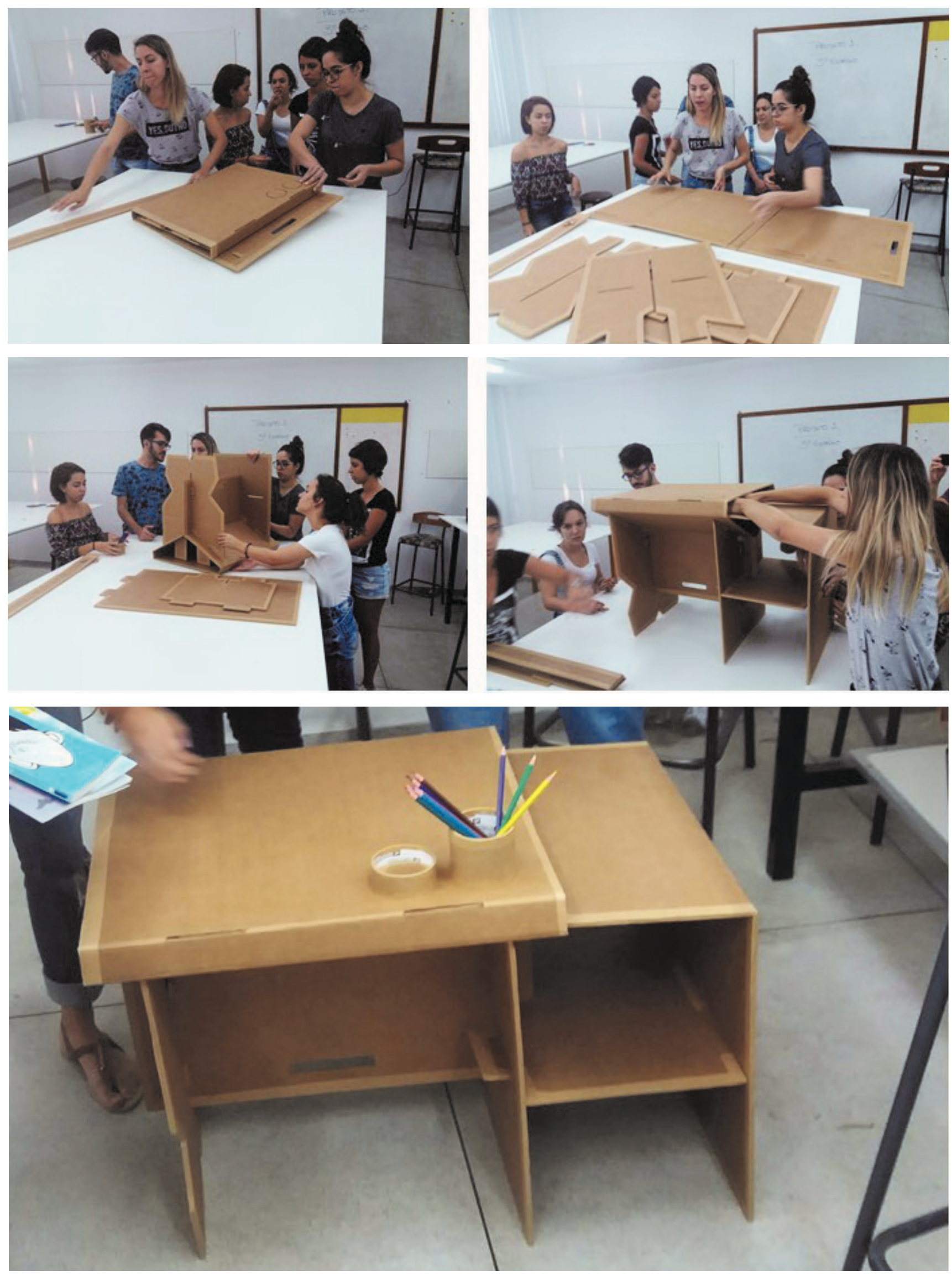

Figura 10 - Mesa de estudos para criança

Fonte: Autores (2018). 

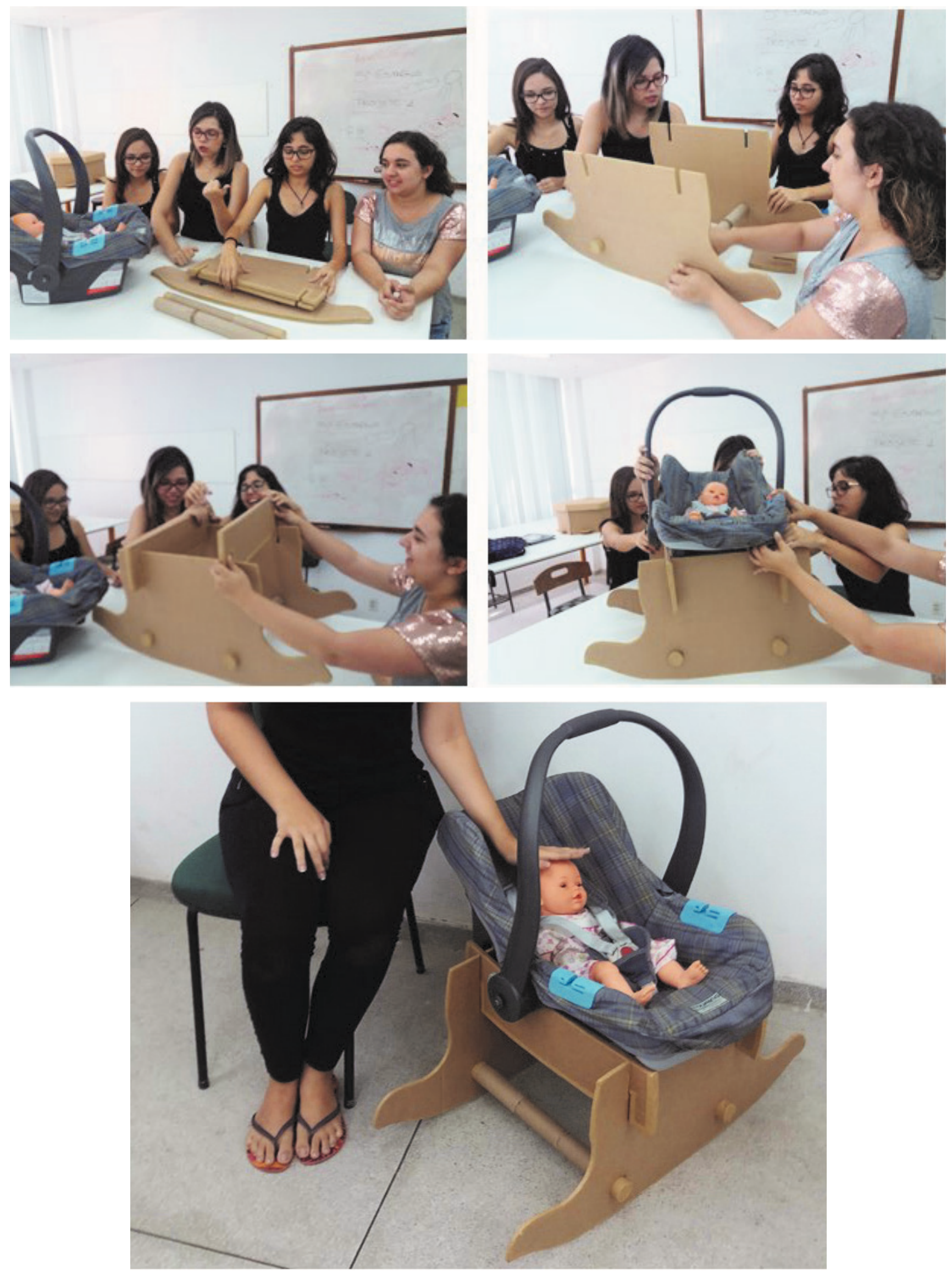

Figura 11 - Suporte para apoio e balanço de bebê conforto Fonte: Autores (2018). 

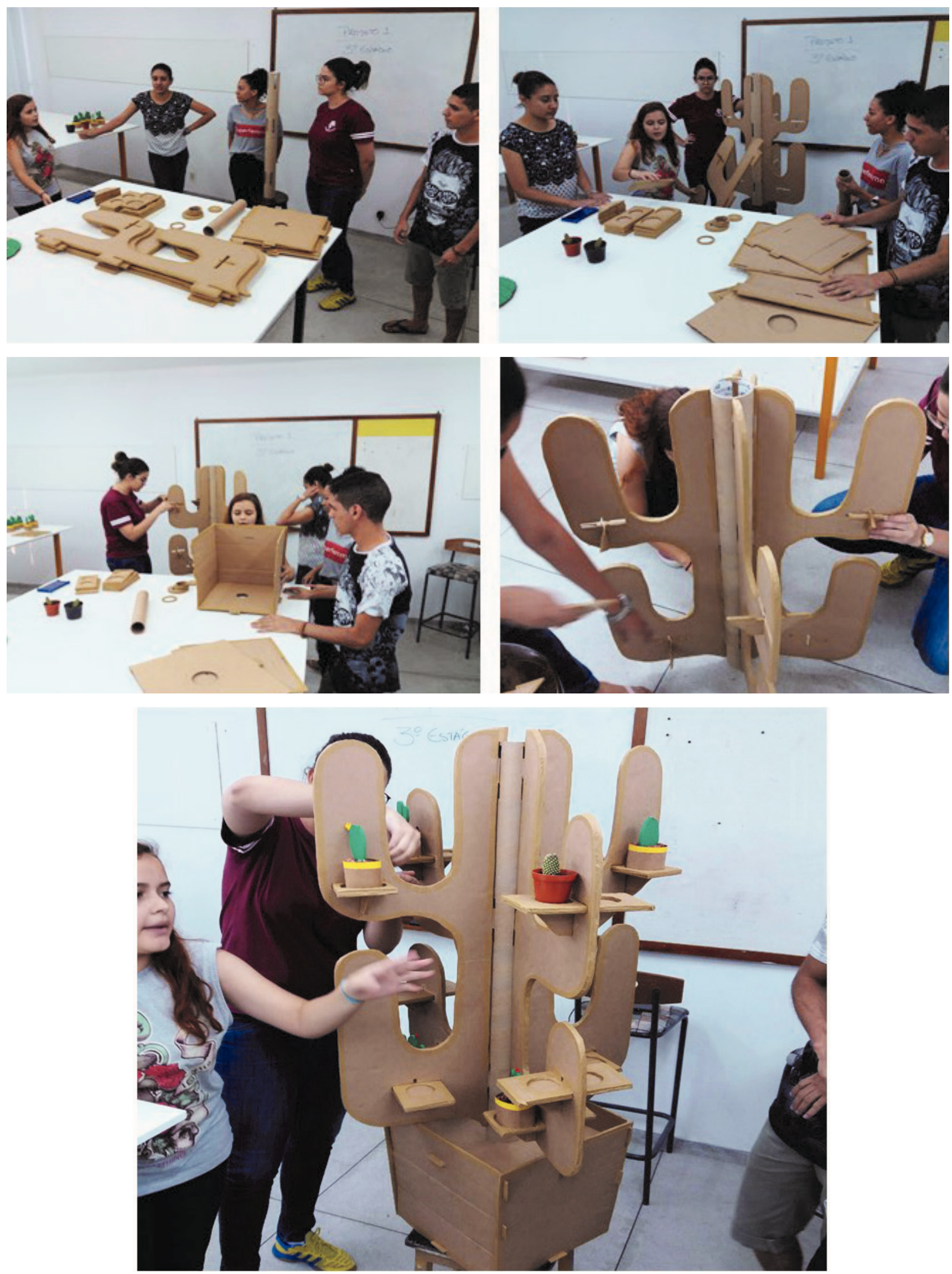

Figura 12 - Expositor de plantas do tipo cactáceas

Fonte: Autores (2018). 

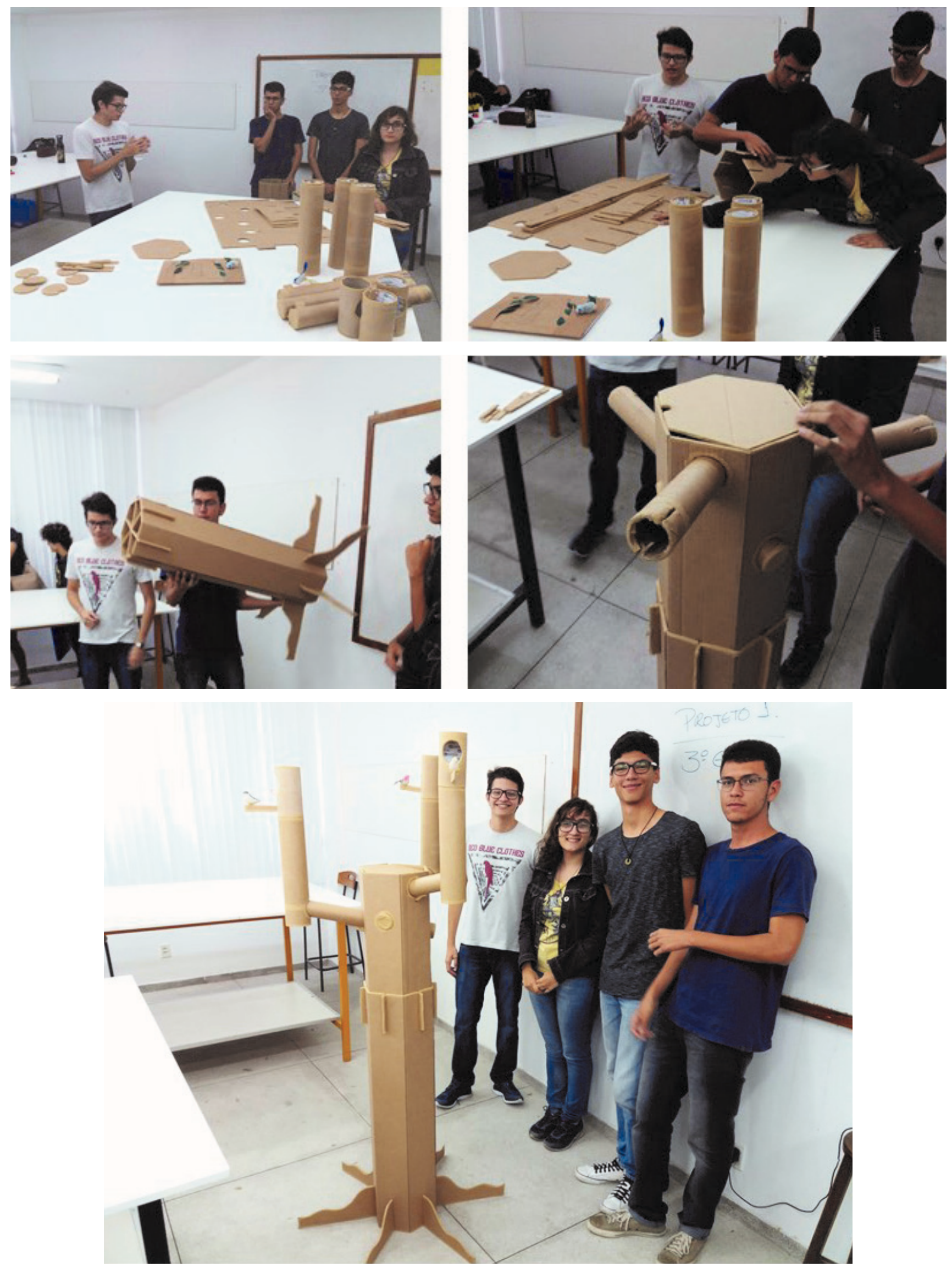

Figura 13 - Viveiro para passarinhos

Fonte: Autores (2018). 
No primeiro produto destaca-se a compactação da estrutura que é apresentada na forma de uma maleta facilitando o transporte, o armazenamento e a proteção das peças a serem utilizadas na montagem do produto. Peças padronizadas, combinação no uso de placas e tubos de papelão e simplificação no sistema de montagem.

No segundo produto é evidente a simplicidade formal e visual. Composição com poucas partes. Uso de um sistema de encaixe eficiente, que permite rápida montagem, desmontagem e a substituição de peças danificadas. Uso do tubo de papelão para dar maior estabilidade ao produto.

No terceiro produto se utiliza da repetição dos módulos. A composição em duas partes principais possibilitando a divisão da atividade de montagem e a redução do tempo de execução. $\mathrm{O}$ uso do descarte de corte das peças maiores para concepção dos componentes menores.

No último produto, verifica-se o uso de conexões e encaixes bem elaborados. A forma hexagonal da estrutura vertical simplifica o processo de construção dando estabilidade ao produto. A parte superior onde fica o ninho do passarinho pode ser retirada para limpeza ou sua total substituição.

\section{CONSIDERAÇÕES FINAIS}

Com relação aos desafios do primeiro estágio foi verificada a dificuldade dos alunos lidarem com recursos limitados de materiais e o controle do tempo para a realização das atividades. No segundo estágio foi identificada a falta de entendimento de como os elementos estruturais e funcionais de um produto se relacionam para alcançar determinado objetivo como fechar, travar, equilibrar, unir, etc. Já no terceiro estágio, o maior problema foi o preconceito sobre o material utilizado (papelão corrugado) que para muitos era considerado de baixo valor e inadequado ao uso. Todavia, após as apresentações, em uma discussão final, os alunos relataram como ponto positivo a inovação no processo metodológico, que abordou a sustentabilidade de forma sequencial, culminando em um produto ecologicamente correto, promovendo uma visão diferenciada sobre a profissão do designer, principalmente em relação ao uso de materiais e processos de produção. Evidenciando assim, o início de uma mudança de comportamento em prol das questões ambientais.

A preparação dos alunos em relação às propriedades dos materiais, suas limitações físicas e o entendimento de sistemas funcionais, auxiliou a execução do produto final. Com relação às práticas sustentáveis apresentadas por Manzini e Vezzoli, constata-se que cada projeto conseguiu contemplar um mix de requisitos apropriados para sua realidade, tais como, compactação da estrutura, utilização de módulos, sistemas de encaixes simples e eficientes, padronização das peças, combinação de elementos (tubos e placas) com o mesmo material, montagem e substituição de partes de forma facilitada e reutilização de resíduos. Por esses motivos, verificou-se que foi alcançado o objetivo de incluir sustentabilidade na fase inicial da graduação.

A adoção de aspectos sustentáveis em disciplinas de projeto assume um papel de conscientização da importância da prática do designer na concepção e materialização de produtos ecologicamente orientados. Contudo existe a necessidade de se continuar a reflexão sobre a sustentabilidade nas outras disciplinas do curso, para fomentar uma mudança significativa no comportamento dos futuros profissionais.

\section{REFERÊNCIAS}

MANZINI, Ezio; VEZZOLI, Carlo. O desenvolvimento de Produtos Sustentáveis: os requisitos ambientais dos produtos industriais. 1 ed. São Paulo: Editora da Universidade de São Paulo, 2011. 366 p.

MANZINI, Ezio. Design para a inovação social e sustentabilidade: comunidades criativas, organizações colaborativas e novas redes projetuais. Rio de Janeiro: E-papers, 2008. 104 p.

KAZAZIAN, Thierry. Haverá a idade das coisas leves: design e desenvolvimento sustentável. 2 ed. São Paulo: Editora Senac são Paulo, 2009. 193 p.

SANTOS, Aguinaldo dos; LOPES, Camila S. D; SAMPAIO, Claudio P; TREIN, Fabiano A; CHAVES, Liliane; Lisiane, LIBRELOTTO; FERROLI, Paulo Cesar; LEPRE, Priscila; ENGLER, suzana; Martins, Viviane. Design para a sustentabilidade: dimensão ambiental. Curitiba: Insight, 2018. 183 p.

VEZZOLI, Carlo. Design de sistemas para a sustentabilidade. 1 ed. Salvador: EDUFBA, 2010. 342 p.

PAZMINO, Ana Veronica; SANTOS, Adriane Shibata. Design e sustentabilidade: necessidade de quebra de paradigma no ensino. Mix sustentável (impresso), v.3, n.1, 2017. p. 10-16.

CALEGARI, Eliana Paula; OLIVEIRA, Branca Freitas de. $A$ sustentabilidade no ensino de design em instituições federais de ensino superior no Brasil. Mix sustentável (impresso), v.3, n.1, 2017. p. 109-118. 


\section{AUTORES}

ORCID: https://orcid.org/0000-0002-0874-9345

ITAMAR FERREIRA DA SILVA, Dr. | Universidade Federal de Campina Grande - UFCG | Unidade Acadêmica de Design/ CCT | Campina Grande - PB, Brasil | Correspondência para: R. Aprígio Veloso, 882 - Universitário, Campina Grande PB, 58429-900, Brasil | e-mail: itamarfs0210@gmail.com

ORCID: https://orcid.org/0000-0003-1323-2831

THAMYRES OLIVEIRA CLEMENTINO, M.Sc. | Universidade Federal de Campina Grande - UFCG | Unidade Acadêmica de Design/CCT | Campina Grande - PB, Brasil | Correspondência para: R. Aprígio Veloso, 882 Universitário, Campina Grande - PB, 58429-900, Brasil | e-mail: thamyres.oliveira.clementino@gmail.com

ORCID: https://orcid.org/0000-0002-3199-0356

LETícIA FREIRE NEGROMONTE | Universidade Federal de Campina Grande - UFCG | Unidade Acadêmica de Design/ CCT | Campina Grande - PB, Brasil | Correspondência para: R. Aprígio Veloso, 882 - Universitário, Campina Grande - PB, 58429-900, Brasil | e-mail: leticiafnegromonte@gmail.com

\section{COMO CITAR ESTE ARTIGO}

SILVA, Itamar Ferreira da; CLEMENTINO, Thamyres Oliveira; NEGROMONTE, Letícia Freire. Metodologia para Inclusão dos Princípios de Sustentabilidade no Ensino de Design de Produto. MIX Sustentável, [S.I.], v. 5, n. 3, p. 81-94, dez. 2019. ISSN 24473073. Disponível em:<http://www.nexos.ufsc.br/index.php/ mixsustentavel>. Acesso em: dia mês. ano. doi:https:// doi.org/10.29183/2447-3073.MIX2019.v5.n5.81-94.

DATA DE ENVI0: $11 / 11 / 2019$

DATA DE ACEITE: 11/11/2019 